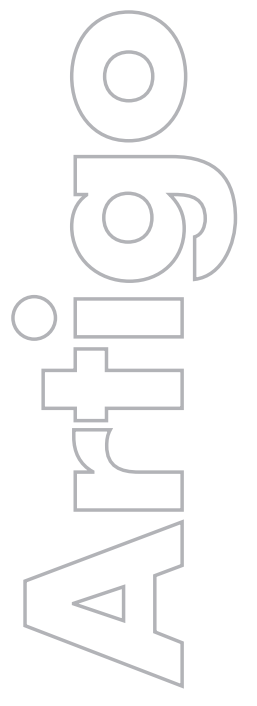

revista

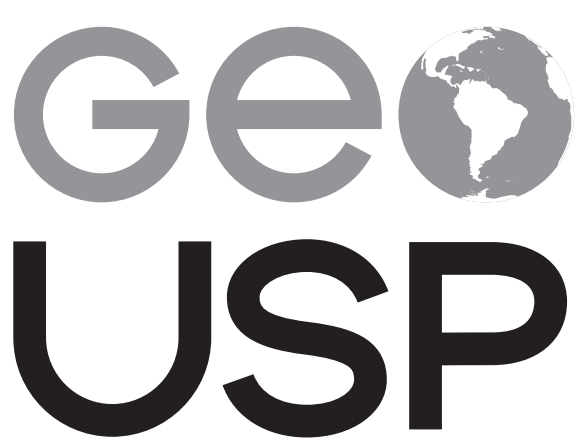

espaço e tempo

Volume $20 \cdot n^{\circ} 3(2016)$

ISSN 2179-0892

\section{Da cidade industrial} segregada à cidade pósindustrial fragmentada: reflexões sobre a (re) produção do espaço urbano na cidade de Pelotas-RS

\author{
Natalia Daniela Soares Sá Britto \\ UFRGS
}

p. $585-601$

Como citar este artigo:

SÁ BRITTO, N. D. S. Da cidade industrial segregada à cidade pós-industrial fragmentada: reflexões sobre a (re)produção do espaço urbano na cidade de Pelotas-RS. Geousp - Espaço e Tempo (Online), v. 20, n. 3, p. 585-601, mês. 2016. ISSN 2179-0892.

Disponível em: <http://www.revistas.usp.br/geousp/issue/ view/6465>. doi: http://dx.doi.org/10.11606/issn.2179-0892. geousp.2014.84539.

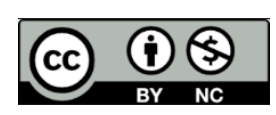

Este artigo está licenciado sob a Creative Commons Attribution 4.0 License. 


\title{
Da cidade industrial segregada à cidade pós-industrial fragmentada: reflexões sobre a (re)produção do espaço urbano na cidade de Pelotas-RS
}

\section{Resumo}

$\bigcirc$ artigo discute o processo de (re)produção do espaço urbano na cidade de Pelotas-RS a partir da análise das ações e das estratégias de agentes públicos e privados na reconfiguração urbana entre 2009 e 2015, destacando o processo de fragmentação socioespacial acompanhada de fenômenos de centralização, suburbanização e periferização do tecido social e urbano. Como mediação teórica, esta análise se apoia em conteúdos e dinâmicas inerentes à transição da cidade industrial segregada do século XX para a cidade pós-industrial fragmentada, marcada pela ampliação do setor de serviços e comércio, assim como pela expansão do setor imobiliário.

Palavras-chave: Cidade pós-industrial. Fragmentação socioespacial. Agentes imobiliários. Poder público. Dinâmica urbana.

From the segregate industrial city to the fragmented postindustrial city: considerations about the (re)production of the urban space in the city of Pelotas-RS, Brazil

\begin{abstract}
This article presents considerations about the process of (re)production of the urban space in the city of Pelotas in Rio Grande do Sul state, Brazil, based upon the analysis of the actions and strategies established among both public and private agents and applied to the urban reconfiguration between 209 and 2015. The socio-spatial fragmentation is highlighted, along with the phenomena of centralization, suburbanization, and peripherization of the social and urban fabric. As its theoretical apparatus, this analysis uses the contents and practices inherent to the transition from the segregate industrial city of the $20^{\text {th }}$ century to the fragmented post-industrial city, characterized both by the growth of tertiary sector and by the expansion of the real estate sector.
\end{abstract}

Keywords: Post-industrial city. Socio-spatial fragmentation. Real estate agents. Public power. Urban dynamic. 


\section{Introdução}

Nos últimos quarenta anos, as intensas transformações tecnológicas, políticas, econômicas e sociais resultantes da endêmica necessidade de reestruturação do modo de produção têm impelido a constante reconfiguração dos espaços urbanos como mecanismo estratégico para a reprodução da mais-valia no capitalismo contemporâneo. Tais transformações se realizam de modo vigente, sobretudo nas cidades cuja produção espacial pretérita foi induzida pelo processo de industrialização e cujas novas dinâmicas no regime de acumulação no capitalismo avançado impelem a crescente diminuição do segundo setor na organização econômica e espacial dessas cidades. Nesses casos, à medida que se aprofunda o arrefecimento da indústria, ampliam-se as atividades financeiras, de informação, comerciais e de serviços, caracterizando o que autores como Ley e Mercer (1980), Salgueiro (1998) e Mendes (2011) denominam cidades pós-industriais. De fato, com o desenvolvimento histórico do modo de produção capitalista, o espaço vem assumindo cada vez mais um papel central na reprodução da mais-valia global, da força de trabalho e, principalmente, das relações sociais de produção. Quanto à reprodução da mais-valia, o circuito secundário se amplia em termos de volume e fluxos de capitais mobilizados, reproduzindo num ritmo incessante as materialidades urbanas num movimento cíclico de construção, destruição e reconstrução das paisagens urbanas, tornando o capital - em sua forma financeiro-imobiliária - expressivo na regulação e reestruturação espacial. A esse respeito, Soja (1993) destaca que desde o período posterior à década de 1970, com a nova onda de reestruturações do capitalismo global, cada vez mais o capital financeiro foi se associando ao Estado na reprodução espacial. Nas palavras do autor:

Como resultado de outra rodada de reestruturação, o capital financeiro tornou-se mais significativo na moldagem do espaço urbano, em conjunção não apenas com o capital industrial, mas também, cada vez mais, com o outro agente de regulação e reestruturação espacial, o Estado (Soja, 1993, p. 126).

Os resultados dessa articulação entre agentes públicos e privados na modelagem dos espaços urbanos pós-industriais se revelam na complexificação do processo de reprodução social e espacial da atualidade. Para Mattos (2006), esse novo momento tem acarretado a constituição de um novo modelo urbano nas cidades latino-americanas, caracterizado pela convergência do modelo concêntrico (anglo-saxão) e do difuso (latino-mediterrâneo), o que acentuaria a composição de cidades policêntricas e fragmentadas com uma morfologia complexa em que "os termos centro e periferia perdem pertinência" (Mattos, 2006, p. 49). Nessa mesma perspectiva, Abramo (2007) chama a atenção para a atuação do mercado de solo formal e informal - na produção de uma estrutura urbana ao mesmo tempo compacta e difusa que ele denomina "cidade com-fusa".

Assim, uma nova configuração urbana se esboça nas cidades geridas sob o signo do capital financeiro e imobiliário, configuração que se traduz na simultânea dispersão, concentração, conjunção e disjunção do tecido social e espacial urbano. Essa tendência pode ser verificada na diversidade e complexidade com que se realizam os padrões de apropriação e dominação do espaço urbano pelos diferentes grupos sociais na contemporaneidade, que ora se orientam para apropriar áreas centrais, ora em direção às regiões periféricas, fazendo com que ambos os padrões ocorram simultânea e desordenadamente. Nesse sentido, são cada vez mais comuns 
os movimentos de reapropriação das áreas centrais pelas camadas sociais de média e alta renda, associados ao surgimento de novos estilos de vida nos quais é visado o consumo de espaços distintos, transformados em função da intervenção de promotores imobiliários e do Estado por meio de projetos de revalorização espacial. Isso tem dado lugar à manifestação de fenômenos como o de gentrificação nos centros tradicionais ou antigas áreas de produção e portuárias.

Nos casos de suburbanização e de periferização (fenômeno típico das cidades latino-americanas), esses padrões acontecem de modo diferente por meio de práticas autossegregatórias dos segmentos de média e alta renda pelo consumo de produtos imobiliários em áreas periféricas, ao mesmo tempo em que se ampliam os processos de segregação compulsória, praticada eminentemente contra grupos sociais excluídos por meio de seu afastamento (material e simbólico) para áreas distantes dos circuitos de valorização imobiliária. Sob as metamorfoses do urbano contemporâneo, ambas as práticas ocorrem simultaneamente, sendo que a definição tradicional da segregação urbana serve apenas como demarcação tênue para esses casos. Salgueiro (1998, p. 39, grifo do autor) define a fragmentação socioespacial como:

[...] uma organização territorial marcada pela existência de enclaves territoriais distintos e sem continuidade com a estrutura socioespacial que os cerca. A fragmentação traduz o aumento intenso da diferenciação e a existência de rupturas entre os vários grupos sociais, organizações e territórios.

Compreendemos a fragmentação como uma das manifestações materiais da produção urbana contemporânea, capaz de identificar pelas formas os conteúdos de uma cidade pós-industrial, caracterizada pela diminuição do papel da indústria no emprego, na renda, nas formas e funções espaciais das cidades. De acordo com Salgueiro (1998, p. 42), a fragmentação pode ser vista como "uma segregação a escala micro, um patchwork ou manta de retalhos em vez da organização em grandes manchas à que nos habituaram". Conforme essa definição, a fragmentação agregaria e acentuaria a segregação socioespacial própria da cidade industrial; porém, seria uma segregação não mais atrelada aos padrões tradicionais das grandes manchas territoriais contínuas e socialmente homogêneas. Tratar-se-ia, assim, de uma segregação pontual, geograficamente localizada e estruturada por grupos sociais cada vez mais polarizados, isolados e diferenciados por meio de enclaves que se distinguem simbólica e materialmente do seu entorno.

Neste artigo, analisaremos essas mudanças na realidade empírica da cidade de Pelotas. A proposta justifica-se pela especificidade histórica e geográfica dessa cidade de porte médio, localizada na Metade Sull do estado do Rio Grande do Sul e que, desde as últimas décadas do século XX, vem passando por uma profunda crise social, espacial e econômica decorrente do processo de desindustrialização local. Não obstante, na última década, a cidade vem

\footnotetext{
A Metade Sul compreende uma subdivisão regional do estado do Rio Grande do Sul, no extremo meridional do estado, na região de fronteira entre o Brasil, o Uruguai e a Argentina. Essa subdivisão regional se baseia tanto em dimensões naturais, sociais e históricas como sobretudo em características econômicas, destacando-se, nesse contexto, pelo desenvolvimento regional desigual em comparação à Metade Norte do Rio Grande do Sul, devido ao baixo dinamismo econômico apresentado no período posterior à década de 1980. Atualmente, é composta por 106 municípios, que se estendem por uma área de $153.879 \mathrm{~km}^{2}$, com uma população de cerca de 2.600 .000 habitantes, o que equivale a $52 \%$ do território gaúcho e a 25\% da população do estado, conforme dados do Censo 2000 (IBGE, 2000). Insere-se, ainda, em um dos 13 Programas de Desenvolvimento Integrado e Sustentável de Mesorregiões Brasileiras, identificadas pelo Ministério da Integração Nacional, para a promoção da integração e do desenvolvimento regional baseada em ações de gestão compartilhada do território, nas escalas intermunicipal, interestadual e nacional.
} 
apresentando um forte impulso na produção do ambiente construído pela expansão do setor imobiliário, fomentada principalmente pela política macroeconômica nacional de habitação e de atração de capitais externos e sustentação das taxas de juros. Acreditamos que esse conjunto de fatores esteja resultando em mutações significativas na morfologia da cidade, sendo a fragmentação uma tendência acentuada deste novo momento. Portanto, fenômenos que já marcavam a paisagem e a vida cotidiana da cidade, organizada pela lógica racional e funcionalista do capitalismo industrial, passam agora a conformar novas dinâmicas e reconfigurações do espaço urbano pelo aprofundamento de padrões segregatórios pretéritos em função da generalização do valor de troca e da concentração de capitais no circuito imobiliário.

\section{A produção do espaço urbano em Pelotas: de centro industrial segregado à cidade pós-industrial fragmentada}

$O$ processo de urbanização em Pelotas teve como ensejo principal o desenvolvimento das forças produtivas fabris, ainda no final do século XIX. De acordo com a historiografia local, o surgimento das primeiras indústrias na cidade ocorreu concomitantemente à crise e decadência do ciclo charqueador na região, que foi gradativamente substituído pela formação de um parque industrial diversificado, constituído por indústrias de médio e grande porte voltadas à produção de bens de consumo não duráveis - sobretudo nos ramos têxtil e de alimentos - e assentadas em relações capitalistas modernas, de trabalho livre e assalariado. Sua produção tinha como destino principal o incipiente mercado consumidor da Campanha Gaúcha, em franca expansão no período, assim como mercados de outras unidades federativas do país, num momento em que as relações de troca entre as regiões ainda se desenvolviam de forma precária em função do isolamento das economias regionais, o que permitiu que as indústrias locais se desenvolvessem protegidas da concorrência externa e com ampla possibilidade de auferir rendimentos da localização relativa. Assim, a particularidade e a importância desse parque fabril na Metade Sul do estado do Rio Grande do Sul foram definidas em função do porte de suas unidades fabris, de sua demanda e do destino de sua produção, que fizeram com que Pelotas se destacasse como um importante polo industrial no período da industrialização dispersa, tendo expressiva relevância em termos de competitividade com outros centros urbanos do mesmo período (Sá Britto, 2011).

Segundo Vieira (2005), é nítido o crescimento populacional na cidade nos primeiros decênios do século XX. De acordo com o autor, entre 1865 e 1900, ocorre o primeiro crescimento substancial da população, que passa de um patamar estabilizado em cerca de 15.000 habitantes para mais de $43.000 \mathrm{em} \mathrm{1900.} \mathrm{Cabe} \mathrm{destacar} \mathrm{que} \mathrm{é} \mathrm{exatamente} \mathrm{nesse} \mathrm{período} \mathrm{que} \mathrm{ocorre} \mathrm{a} \mathrm{fun-}$ dação da primeira grande indústria de Pelotas, a F. C. Lang, voltada para a produção de velas e sabão. Já nas décadas seguintes, a composição demográfica do município cresce num ritmo acelerado, chegando aos quase 128.000 habitantes na metade do século. Tal fenômeno se realizou eminentemente sobre o espaço urbano, tendo em vista que, em 1950, mais de 64\% da população pelotense vivia na cidade. Assim, podemos conjeturar que o início da urbanização esteve diretamente relacionado ao primeiro surto industrial da cidade, tendo em vista o importante papel da atividade fabril na atração de um amplo contingente populacional do campo e das cidades vizinhas, assim como no agenciamento da autonomia política e econômica do urbano, o que mudou profundamente os padrões de densificação e organização social e funcional do espaço. 
Em termos funcionais, o espaço passou a ser organizado de acordo com a lógica da reprodução do capital, sendo apropriado pelos setores produtivos como modo de assegurar vantagens locacionais para o desenvolvimento das atividades fabris e do comércio. Seguindo o padrão organizacional característico da industrialização fordista, as primeiras unidades fabris se concentraram nas áreas em que havia maior disponibilidade de infraestruturas e equipamentos indispensáveis para a realização do processo produtivo, enquanto as atividades ligadas ao comércio e à exportação ocupavam aquelas áreas já consolidadas da cidade colonial, ${ }^{2}$ cuja localização possibilitava a complementaridade com as áreas destinadas à moradia e à produção. Assim, delineava-se uma cidade segregada funcional e socialmente, com seu espaço diferenciado em termos de usos e funções, evidenciando em sua dinâmica interna a complementaridade entre suas grandes zonas homogêneas.

Moura (2006a) enfatiza que, nas primeiras décadas do século XX, os problemas relacionados à ausência de moradia e insuficiência das infraestruturas existentes -concentradas no núcleo central consolidado da cidade e apropriadas pelos segmentos de alta renda e pelo capital produtivo - começam a impactar diretamente a vida na cidade, resultando no alastramento dos cortiços e das habitações precárias para as camadas populares, assim como na proliferação de epidemias e doenças. Diante dessa insuficiência da cidade colonial frente à intensa urbanização fordista, o Estado passa a atuar pontualmente na modernização da cidade, instituindo uma série de aparatos jurídicos a partir de uma postura política que privilegiava a higienização e racionalização do espaço como mecanismo de controle e coerção das forças sociais assim como de reprodução das forças produtivas e do capital. Nesse sentido, a autora destaca que a atuação do Estado assumiu duas tônicas distintas: uma na criação de regramentos e racionalização do espaço, por meio dos códigos de obras, posturas e incentivos fiscais, e outra na ação coercitiva, que assegurava os padrões de apropriação espacial e reprodução do capital industrial na cidade pela retirada dos cortiços existentes e da repressão a novas construções nas áreas de valorização.

Ao lado dessas ações, a autora destaca o distanciamento do Estado quanto à implementação e execução de uma política habitacional que enfrentasse diretamente o problema de falta de moradia para a população mais pobre, delegando essa questão à iniciativa privada pela criação de leis de incentivos fiscais que buscavam promover a construção de casas de aluguel, vilas operárias e loteamentos na periferia do núcleo urbano, fomentando, com isso, o surgimento dos primeiros promotores imobiliários profissionais na cidade. É importante destacar que, nesse momento, a questão da habitação popular se configurava como uma demanda importante para o desenvolvimento do setor produtivo, tendo em vista o papel da moradia na reprodução da força de trabalho para a indústria nascente e na reprodução das relações sociais de produção num sentido mais amplo. Por esse motivo, foi recorrente na primeira metade do século XX a construção de vilas e casas geminadas pelos donos das fábricas, principalmente nas áreas subjacentes às unidades fabris, o que possibilitava a reprodução e o controle do operariado na cidade, além de fornecer um circuito permanente de investimento para o setor industrial pelas possibilidades de acumulação rentista da terra e da criação de reservas para o capital produtivo.

2 A fundação da cidade de Pelotas esteve ligada ao desenvolvimento da atividade saladeiril iniciada na região no fim do século XVIII. A produção e o comércio do charque para todo o território brasileiro no período colonial permitiram grande acumulação de riqueza nas mãos de uma elite local, que destinaria parte desse acúmulo à construção da cidade. Nesse contexto histórico-econômico, tanto as funções quanto as formas do núcleo urbano inicial corresponderam ao modelo de cidade colonial brasileira, com ampla influência dos traçados português e espanhol. 
Como resultado dessa política estatal atrelada aos interesses do capital industrial, configurou-se um espaço apropriado de modo desigual, marcado pela valorização diferenciada do solo, decorrente da relação entre o provimento de infraestruturas desiguais e a livre atuação dos agentes privados, interessados nas potencialidades de utilização rentista da terra. Em decorrência desse tipo de produção, iniciou-se um processo de dispersão da malha urbana, primeiro na direção sul e leste e, posteriormente, em direção aos eixos oeste e norte, caracterizando um padrão espacial difuso, conforme observamos na Figura 1 (Soares, 2002). De acordo com essa configuração, o centro manteve-se valorizado pela concentração de infraestrutura e obras de modernização, controlado em termos de padrões habitacionais e apropriado pelos segmentos de alta renda, enquanto a periferia se expandia com precárias condições de infraestrutura, mobilidade e moradia, dependente principalmente da capacidade autoconstrutiva familiar dos trabalhadores.

\section{Figura 1 - Evolução urbana entre 1815 e 1922 e localização das primeiras indústrias de Pelotas de 1880 a 1940}

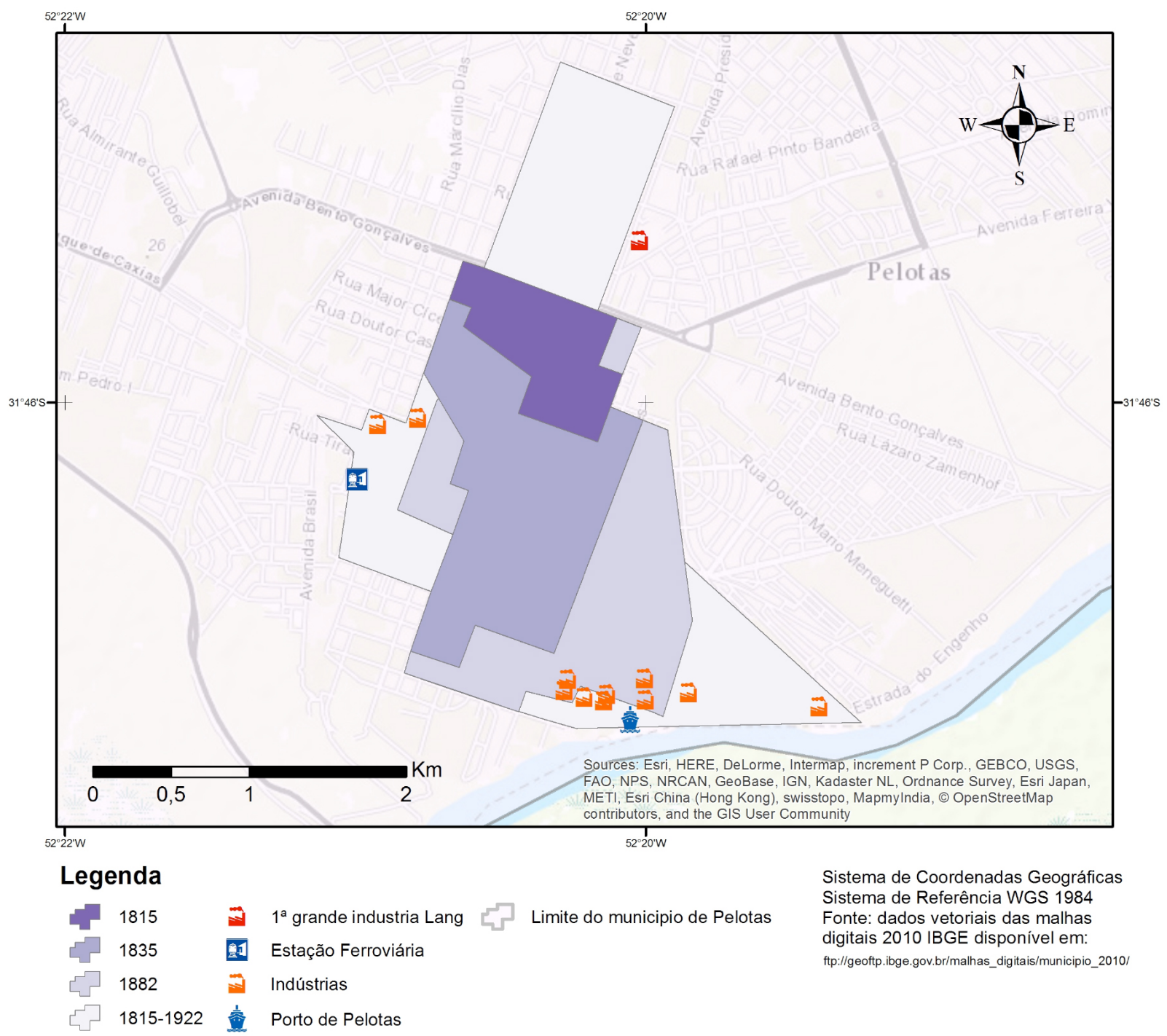

elaborado por: Éder Luís Rodrigues (2016). 
No final da década de 1930, a cidade passa a apresentar os primeiros sinais da retração do desenvolvimento fabril, resultantes especialmente das transformações na política econômica instituídas em escala nacional a partir do advento do Estado Novo e da ampliação da política de substituição de importações, o que elevou consideravelmente os patamares da industrialização no país. Tal conjuntura resultou na concentração de importantes obras de infraestrutura e recursos federais no eixo sudeste do país, que fez com que as antigas regiões industriais isoladas perdessem força frente ao aumento da concorrência com as indústrias do Sudeste, sobretudo aquelas localizadas no eixo São Paulo-Rio de Janeiro. Em Pelotas, um número expressivo de unidades fabris - que concorreram diretamente com a indústria paulista nesse período - acabaram por fechar as portas, instaurando um primeiro processo de desindustrialização na cidade. Em contrapartida, o setor terciário permaneceu em franca expansão em função das demandas de um crescente mercado consumidor formado pela intensificação do processo de urbanização.

Apenas no início da década de 1970, com uma nova rodada de transformações políticas e econômicas, intensificou-se novamente o processo de urbanização/industrialização local, principalmente a partir da formação de um novo parque industrial, desta vez ligado à complementaridade entre a produção rural e industrial. Influência direta da política econômica que emergiu no período pós-1964, o complexo agroindustrial de Pelotas acentua a especialização industrial no ramo alimentício pela ampliação das indústrias de beneficiamento de arroz, frigoríficos, curtumes e indústria de conservas vegetais, que fortalece a relação entre o campo e a cidade. De acordo com os censos industriais (1960-1970-1975), a evolução no número de unidades industriais, entre 1960 e 1975, foi de mais de 200 novas unidades. Essa retomada do crescimento da indústria se relaciona com uma série de políticas estatais que acabaram facilitando o desenvolvimento do setor, beneficiado por linhas de crédito e financiamento internacional, assim como pela redução de impostos e incentivos fiscais decorrentes da reforma tributária de 1969 e do chamado "milagre econômico" brasileiro. A expansão industrial desse período coloca Pelotas novamente em posição de destaque na economia gaúcha, que, por sua vez, atinge taxas superiores de crescimento em relação aos demais centros industriais do Brasil (Sá Britto, 2011).

No âmbito urbano, esse período foi marcado por vultosos investimentos na produção do ambiente construído, especialmente por obras de infraestrutura e da produção de moradia por meio do Sistema Financeiro de Habitação (SFH) e da criação do Banco Nacional de Habitação (BNH). Nesse momento, consolida-se a intervenção estatal na produção de unidades habitacionais em larga escala, privilegiando a construção dos grandes conjuntos habitacionais para as classes de baixa e média renda, como parte de uma política habitacional que se afirmara pela produção mercantil da moradia, de forte intuito político e ideológico, e como modo de assegurar o desenvolvimento de uma política econômica fundada no desenvolvimento do ramo da construção civil. Em Pelotas, a instituição do BNH significou a criação de um canal permanente de financiamento para a produção habitacional, o que favoreceu o desenvolvimento do setor imobiliário local. De acordo com 
Soares (2006), muitas empresas que cresceram e se destacaram nesse período faziam parte de grandes grupos econômicos locais do capital produtivo e agropecuário, sobretudo no ramo da rizicultura, que passavam a atuar também no ramo imobiliário, evidenciando com isso a intensa transferência de capitais industriais do campo e do comércio para o circuito secundário.

Chiarelli (2014) destaca que, nesse período, se observaram três tipos de produção habitacional predominantes na cidade: (a) a construção de grandes conjuntos habitacionais a partir da formação de cooperativas municipais, que, na verdade, eram instituídas a partir de empresas privadas do ramo da construção civil e que fundavam as ditas "cooperativas", controlando todo o processo produtivo como modo de angariar recursos via $\mathrm{BNH}$; (b) as produções oriundas dos projetos executados pelas Companhias de Habitação Estaduais (Cohabs), provenientes da parceria entre o governo do estado e o governo federal; e (c) por fim, as produções habitacionais realizadas por operadores privados, ou seja, por construtoras locais que elaboravam projeto e executavam as obras, sendo estas financiadas pelo BNH. Soares (2006) enfatiza também que nessa última forma de produção, enquanto o Estado assumia os riscos dos negócios pela disponibilização dos recursos via financiamento, o capital imobiliário apenas acumulava os benefícios pela captação de grandes volumes de recursos do Estado.

O resultado dessa conjuntura foi uma produção sem precedentes do ambiente construído, o que impactou fortemente a dinâmica e a morfologia urbana assim como o fortalecimento do setor imobiliário em Pelotas. Sobre a segregação socioespacial resultante desse processo, Soares destaca que:

Os conjuntos habitacionais foram importantes na definição de novas áreas de expansão dos empreendimentos privados e, especialmente, para a definição das áreas de classe média da cidade, geralmente localizadas próximas a esses conjuntos. Por outro lado, na área central predominava outro tipo de operação imobiliária. Aqui os operadores construíram edifícios de uso comercial (consultórios, escritórios) e edifícios de apartamento para setores de alta renda (Soares, 2006, p. 169-170).

Nesse contexto, constituíram-se grandes bairros a partir da instalação dos conjuntos habitacionais em áreas afastadas do núcleo central. Isso gerou uma elevada densificação em virtude da enorme quantidade de unidades habitacionais que cada conjunto continha, que acabaram por agir como força motriz na dispersão da malha urbana em direção às periferias, conforme se observa na Figura 2. Exemplos desse processo podem ser observados no eixo norte de expansão da cidade, sendo expressivos os casos da Cohab Lindoia e Cohab Pestano, conjuntos construídos no fim da década de 1970 em uma área de transição entre o perímetro urbano e a zona rural - com uma distância superior em relação ao núcleo central para a época -, o que forçou a extensão da malha urbana em direção ao vetor norte da cidade. 


\section{Figura 2 - Evolução urbana entre 1815 a 1988 e localização dos empreen- dimentos residenciais lançados pelo BNH de 1964 a 1980}

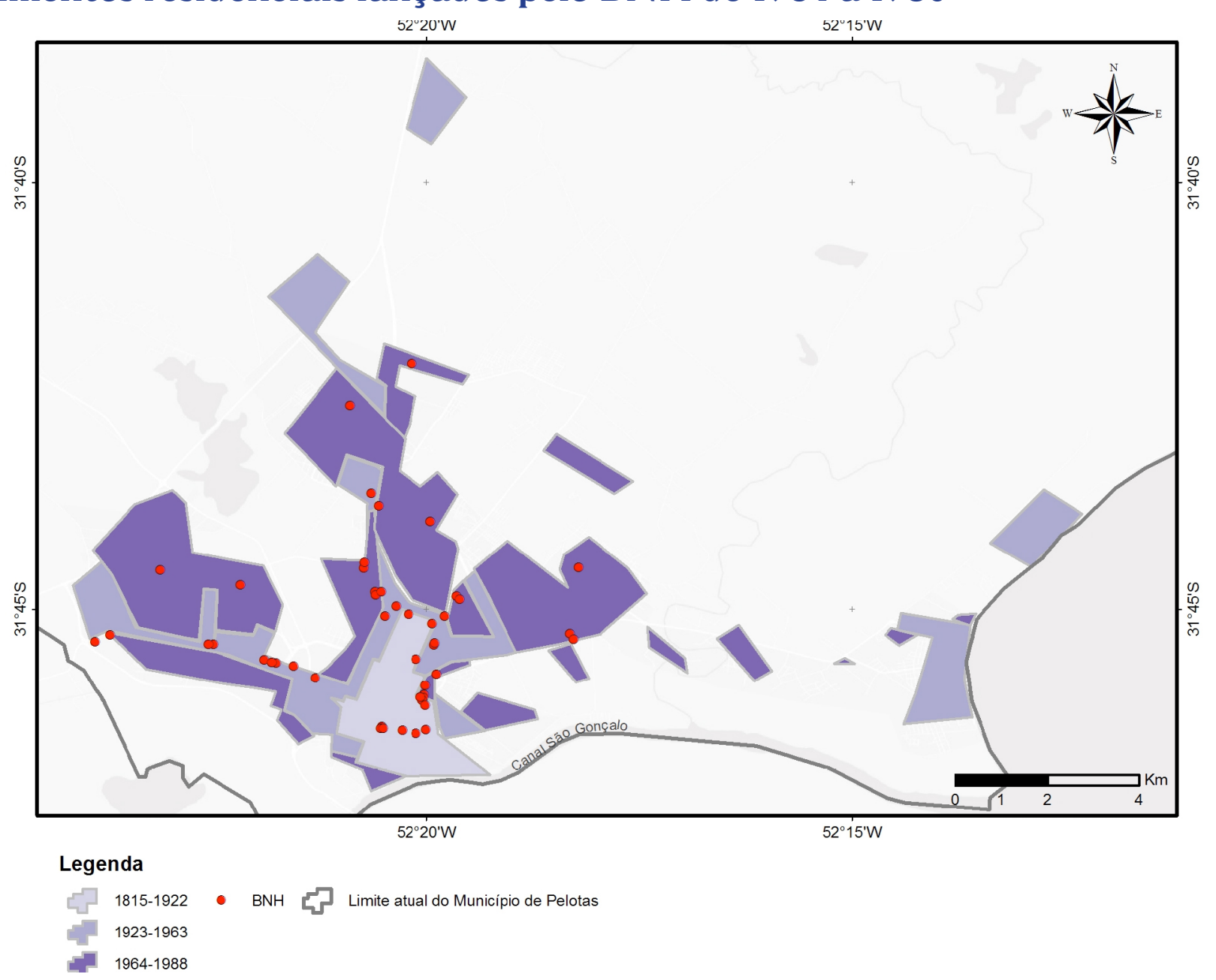

elaborado por: Éder Luís Rodrigues (2016).

No início dos anos 1980, com o desmantelamento do estado de exceção e com o fim do "milagre econômico", Pelotas começa a atravessar um extenso período de crise, recessão e estagnação econômica, agravada pelo deslocamento e encerramento de importantes indústrias do ramo alimentício, que perduraria por toda a década de 1980, avançando nos anos 1990 e chegando à virada do novo século sem apresentar melhoras. De acordo com Ferreira (2011), entre os anos de 1980 e 2000 houve uma significativa diminuição no número de empresas industriais do ramo de alimentos em Pelotas, que passaram de um total de 40 unidades produtivas para apenas 12 empresas na virada do século. De tal modo, as décadas de 1980 e 1990 foram marcadas pelo crescente desemprego e empobrecimento da classe trabalhadora, acompanhado pela precarização das relações de trabalho, sobretudo no setor terciário, que se manteve estável em função do crescimento da população e do papel polarizador que Pelotas exerce em relação aos municípios da Metade Sul do estado. No cenário nacional, no período vivencia-se o avanço do receituário neoliberal a partir da consagração do Consenso de Washington, cuja principal consequência foi a diminuição da atuação do Estado, sobretudo nas políticas sociais e de desenvolvimento regional, seguida pela abertura econômica, desregulamentações, privatizações e a intensificação da internacionalização do capital, o que colabora para a intensificação da crise local. 
Assim, a sobrevida do município se deve, até os dias atuais, às atividades comerciais e de serviços, assim como à concentração de instituições públicas, como universidades, órgãos estaduais e federais, exército, entre outros, que desempenham papel importante na captação de recursos e na renda de parte da população.

\section{A expansão do capital imobiliário na cidade pós-industrial: articulação entre agentes públicos e privados na (re)produção do espaço urbano}

Nos últimos anos, uma intensa onda de reprodução do ambiente construído tem despertado a atenção sobre a cidade, que, aparentemente, inicia um novo ciclo de acumulação ancorado no setor da construção civil e imobiliário. Esse novo impulso relaciona-se diretamente à política macroeconômica adotada no país, sobretudo após 2009, que direcionou para a região amplos recursos federais por meio da implementação de obras de infraestrutura, habitação, ensino e transportes. Como destacado anteriormente, durante várias décadas, a região de Pelotas manteve-se economicamente estagnada, marcada pelo crescente agravamento das mazelas socioespaciais e por uma total carência de políticas públicas de desenvolvimento local e regional capazes de modificar tal cenário. Será com a implementação do PAC 1 e 2, nos anos posteriores a 2007, que novamente a cidade passará a ser inserida nos eixos de modelagem e ordenamento do território nacional pela concentração de investimentos na região.

Entre esses investimentos, o de maior impacto regional foi a implantação do Polo Naval e offshore na cidade de Rio Grande, distante cerca de $60 \mathrm{~km}$ de Pelotas e que, junto a essa cidade e outros três municípios, conforme a Aglomeração Urbana do Sul. ${ }^{3}$ Desde 2007, a composição portuária de Rio Grande vem concentrando novas estruturas voltadas à montagem e construção de plataformas de petróleo encomendadas pela Petrobrás, como extensão de uma nova orientação política da Agência Nacional do Petróleo e do Governo Federal que tem como objetivo principal impulsionar a indústria naval brasileira por meio de licitações que favoreçam a produção nacional, além de promover uma reorganização espacial do parque naval brasileiro, fazendo com que recursos antes concentrados no Rio de Janeiro sejam direcionados para outras regiões do país. Em termos de recursos públicos e privados, estima-se que, até o ano de 2020 - quando deverão cessar as licitações da Petrobras -, a região deverá receber investimentos da ordem dos 13 bilhões de reais, o que estimulará a instalação de setores estratégicos e complementares às atividades navais e portuárias, suscitando, assim, o desenvolvimento de um novo ciclo industrial em Rio Grande, com grande destaque para as empresas que atuam nos ramos químicos, metalúrgico, madeireiro, de alimentos e de energia (Domingues; Carvalho; Carvalho, 2013).

Segundo Domingues, Carvalho e Carvalho (2013), o prognóstico para a região aponta que esse conjunto deverá gerar mais de 100.000 vagas de empregos diretos e indiretos até 2020, fazendo com que Rio Grande dobre de tamanho devido aos intensos fluxos migratórios atraídos para a cidade em decorrência da carência de mão de obra local especializada para o setor. Assim, o município que, em 2010 (IBGE, 2010), possuía pouco mais de 197.000 habitantes, poderá dobrar esse índice em alguns anos, atingindo a margem de 400.000 habitantes. Em

3 A Aglomeração Urbana do Sul é formada pelos municípios de Rio Grande, Pelotas, Capão do Leão, São José do Norte e Arroio do Padre, concentrando uma população de cerca de 600 mil habitantes, num raio de 60 km. Entretanto, a especificidade da Ausul é o fato de não possuir um núcleo central dominante e não apresentar continuidade da mancha urbana (conurbação), o que impossibilita sua caracterização como área metropolitana (Soares, 2006). 
termos regionais, esse acréscimo significaria a composição de uma população aproximada de um milhão de habitantes na Aglomeração Urbana do Sul, que passaria a conformar um grande centro urbano regional paralelo à Região Metropolitana de Porto Alegre, capital do estado.

Isso tem feito que alguns gargalhos de infraestrutura e equipamentos urbanos começassem a despontar, sobretudo ligados à criação das condições gerais de reprodução dessa força de trabalho e principalmente pautados pela questão da habitação. Nos últimos anos, por exemplo, as estratégias de acumulação rentista por parte de proprietários de terras e promotores imobiliários de Rio Grande geraram uma onda de valorização dos imóveis na cidade, fazendo com que os preços inflacionassem em um curto período de tempo. Do mesmo modo, a insuficiência do setor local da construção civil e imobiliário - com baixa capacidade produtiva para a efetivação de novos produtos para tal demanda -, juntamente com as características fisiográficas da cidade - que possui limites naturais para a expansão territorial -, fortaleceram o caráter de Pelotas como polo regional de serviços, sobretudo pela oferta de moradia (Feijó; Madono, 2013). De acordo com o Sindicato das Empresas de Compra, Venda, Locação e Administração de Imóveis de Pelotas (Secovi), a procura por imóveis em Pelotas alcançou os maiores índices entre os anos de 2008 e 2010, fazendo com que ocorresse também nessa cidade uma vertiginosa valorização dos imóveis, que chegaram a quadruplicar seus valores na última década. Ainda segundo o Sindicato, essa valorização se relaciona de modo direto com as transformações ocorridas na cidade vizinha de Rio Grande e com os investimentos alocados nela, já que o fluxo de trabalhadores polarizados por Rio Grande ampliou consideravelmente a demanda por moradia em Pelotas (Zero Hora, 2012).

Nesse contexto, o aumento da demanda por novas moradias tem conduzido a uma ampliação das ações e estratégias dos agentes imobiliários locais e regionais, que, estimulados pelas possibilidades de rápida acumulação via produção habitacional, tem atraído capitais de origem produtiva, do campo e financeiro para a produção do ambiente construído em Pelotas. Frente a isso, uma série de novos empreendimentos residenciais foi anunciada na cidade nos últimos anos, voltando-se para os diferentes segmentos de renda e com uma grande diversidade de tipologias, evidenciando com isso um aquecimento no setor imobiliário local. Entre eles, os lançamentos de alto padrão têm chamado a atenção na cidade e, tendo em vista o longo período de crise econômica e social vivenciado nas décadas recentes e que, nesse momento, contrastam de forma patente com esses novos padrões de produção das materialidades urbanas próprios de cidades com grande concentração de capitais e com composição de uma significativa parcela social de alta renda. Exemplos como a construção de um condomínio horizontal fechado pelo grupo Alphaville, ${ }^{4}$ localizado na periferia leste da cidade em direção ao Balneário do Laranjal, suscitam questionamentos sobre as causas e consequências desses processos de produção. Outro grande empreendimento de destaque, nesse mesmo escopo, foi o anúncio da construção do primeiro "bairro sustentável" do Brasil, assinado pelo escritório de arquitetura de Jaime Lerner, em associação com as empresas Joal Teitelbaum Escritório de Engenharia e o grupo financeiro Guapo Capital Group. O projeto prevê a produção de três mil unidades habitacionais para mais de nove mil habitantes apresenta forte apelo à questão ambiental, por meio do conceito de bairro susten-

4 Com investimentos superiores a $\mathrm{R} \$ 42$ milhões, o projeto prevê a construção de 273 casas em terrenos residenciais que variam de $400 \mathrm{~m}^{2}$ a $600 \mathrm{~m}^{2}$, para uma população estimada de 1.092 habitantes. $\bigcirc$ empreendimento, já feito em outros 18 estados brasileiros - e o sexto no Rio Grande do Sul -, enquadra-se na tipologia de condomínio fechado, autogestionário, com infraestrutura e equipamentos internos particulares distribuídos entre áreas privativas de lazer, esportes e comércio. 
tável que embasa o Plano Diretor interno e o projeto de sustentabilidade, e conta com amplos investimentos em publicidade, inclusive em uma escala de abrangência nacional. ${ }^{5}$ De acordo com o projeto, estão previstos investimentos de dois bilhões de reais ao longo dos oito primeiros anos.

Concomitantemente às transformações na cidade vizinha de Rio Grande, outras políticas federais aplicadas na escala local também contribuem para esse dinamismo do setor imobiliário em Pelotas. Uma delas relaciona-se à expansão no número de vagas e cursos oferecidos pela Universidade Federal em Pelotas (UFPel), decorrente de sua adesão ao Programa de Apoio à Reestruturação e Expansão das Universidades Federais (Reuni). Desde 2007, ano da adesão ao programa, até 2012 , foram criados 48 novos cursos na instituição, o que significou um acréscimo de mais de 8.000 novas vagas na modalidade presencial e de 5.000 a distância, com recursos que chegaram à ordem dos 33 milhões de reais. Do mesmo modo, a adoção do sistema de ingresso por meio do Exame Nacional do Ensino Médio e do Sistema de Seleção Unificado (Enem/Sisu) impulsionou a atração de estudantes de outras regiões do país para a cidade. Tendo esse público específico, em expansão, como alvo, muitas incorporadoras passam a reorientar suas práticas com vistas à exploração da função de "cidade universitária". Isso significou um aumento na produção e oferta de produtos imobiliários com tipologias exclusivas para o público universitário, dominando a oferta de apartamentos de um dormitório, quitinetes e lofts.

Ao mesmo tempo, esses novos produtos têm uma concentração espacial que vem se refletindo em transformações no uso e na apropriação do território, na medida em que vem provocando um crescente processo de valorização dos imóveis no lugar, até então caracterizado pelos usos industriais, portuários e de residência do ex-proletariado pelotense, assim como de grupos sociais de baixa renda que vinham ocupando a área nas últimas décadas em função do baixo custo do solo, resultante da supressão das atividades produtivas. Com a valorização e a apropriação pelo público ligado à universidade tem-se observado o crescente abandono da área por parte dos ex-operários e grupos sociais de baixa renda, que já não podem pagar o alto custo dos aluguéis, configurando-se assim um possível processo de gentrificação do lugar.

Por fim, a política habitacional de nível federal é a que de fato vem repercutindo, na última década e de forma estrutural, na composição e organização do setor da construção civil e imobiliária em Pelotas. Desde 2003, com a implantação do Programa de Arrendamento Residencial (PAR), o setor imobiliário local vem apresentando grande crescimento e dinamismo nas formas de produção adotadas, tornando-se referência regional na produção de moradia para a chamada "classe C". Segundo dados apresentados pela Superintendência Regional Extremo Sul da Caixa Econômica Federal (Marques, 2013), entre 2003 e junho de 2010, foram entregues mais de 18 conjuntos habitacionais pelo PAR, contabilizando um total de 3.177 moradias, com investimentos da ordem dos $R \$ 84,3$ milhões. Nesse cenário, conforme destaca Soares (2006, p. 184), Pelotas passou a ser considerada "o segundo município brasileiro em número de empreendimentos e unidades habitacionais construídas" por meio desse programa, tornando-se inclusive referência na produção de moradia para o referido segmento de renda.

Já em 2009, com a consolidação do Programa Minha Casa Minha Vida (PMCMV), os agentes imobiliários locais ampliaram consideravelmente sua escala de atuação, consolidando o setor em função da acumulação propiciada pelo grande volume de capital mobilizado pelo

5 Além da intensa publicidade em jornais de circulação local e regional, publicaram-se anúncios em escala nacional, como no site da rede de supermercados Pão de Açúcar, do Rio de Janeiro, fazendo referência ao projeto como sendo o primeiro bairro sustentável do Brasil. 
PMCMV na região, que, em apenas quatro anos, alcançou o valor de $\mathrm{R} \$ 279,97$ milhões de reais na realização de 23 empreendimentos com 5.413 unidades habitacionais distribuídas entre as faixas 1,2 e 3 do programa. Nos casos da faixa 1, voltada à produção de moradia para as famílias com renda de até 3 salários mínimos, atualmente operam cerca de nove empresas na cidade, sendo que cinco delas já atuavam na produção para as classes de baixa e média renda por meio de empreendimentos residenciais ligados ao PAR.

Todavia, apesar da ampliação no número de unidades habitacionais promovida pelo PMCMV, uma série de problemas provocados pelos padrões de localização adotados pelas empresas construtoras tem revelado as fragilidades em relação à inclusão, ao acesso a esses novos empreendimentos, bem como a seu uso. Entre esses problemas, o da ampliação do processo de periferização das camadas de baixa renda tem sido significativo na definição da estrutura socioespacial da cidade, expondo a ausência de articulação entre a política habitacional e a política urbana local.

Em sua maioria, a localização de tais empreendimentos tem sido definida em função dos interesses e das estratégias dos agentes imobiliários, que, de acordo com as regras do PMCMV, são os responsáveis pelos empreendimentos desde a sua concepção (estudo de mercado, definição de tipologias, localização) até a sua conclusão (construção e comercialização). Essa livre atuação acaba resultando na contradição entre as orientações dispostas no plano legislativo (por exemplo, nas Áreas de Interesse Social do Plano Diretor Municipal) e as ações concretas de localização dos empreendimentos, definidas exclusivamente em função das estratégias de acumulação do setor imobiliário. Um exemplo dessa contradição é caso do Residencial El Dourado, um dos primeiros empreendimentos realizados pelo programa na cidade. Desde sua conclusão, no ano de 2011, os moradores vêm denunciando junto ao Ministério Público e a órgãos de imprensa, uma série de problemas relacionados à ausência de segurança, infraestrutura urbana básica e equipamentos de consumo coletivo em função de sua alocação em uma área distante da malha urbana consolidada.

Atualmente, atuam mais de 20 empresas na faixa 2 e 3 do PMCMV em Pelotas, sendo expressiva a penetração no mercado local de grandes incorporadoras nacionais. Do mesmo modo, especialmente nos últimos quatro anos, a produção de moradia para esse segmento de renda tem sido dominante na cidade, o que contrasta com o déficit habitacional básico no município. Segundo a Caixa Econômica Federal (2011), o déficit de habitação no município, no ano de 2009, foi de 10.675 moradias, sendo assim a segunda cidade do estado com maior carência de habitação, representando cerca de 5\% da demanda habitacional de todo o estado do Rio Grande do Sul. Entretanto, o relatório do Plano Local de Habitação de Interesse Social, elaborado pela Prefeitura Municipal de Pelotas (2012), revela que cerca de $90 \%$ das famílias demandantes cadastradas pela prefeitura enquadram-se na faixa de renda de 0 até 1 salário mínimo, ou seja, correspondem à faixa 1 do PMCMV.

Diante de tal descompasso, fica evidente a vinculação do programa, no âmbito local, à produção mercantil da moradia, já que a orientação se desloca da faixa na qual se concentra majoritariamente o déficit habitacional da cidade para atender as faixas 2 e 3 do PMCMV, percebidas como mais rentáveis pelos promotores imobiliários em face dos subsídios governamentais concedidos e do acesso facilitado ao crédito imobiliário para esse segmento 
de renda. Como destaca Shimbo (2010), trata-se de um novo momento da produção das cidades brasileiras, caracterizado pela constituição de uma forma inédita de empresariamento da produção da habitação, na qual se intensifica a articulação entre Estado, empresas construtoras e capital financeiro na produção do espaço urbano, modificando, com isso, tanto a estruturação do mercado imobiliário, que agora passa a direcionar-se para o chamado segmento econômico por meio da "habitação social de mercado", como os ritmos e padrões de produção das materialidades urbanas.

Em seu conjunto, essa nova rodada de produção das materialidades urbanas em Pelotas verificada nos últimos anos pôde ser identificada pela diversidade de artefatos arquitetônicos que concorrem para definir novas formas de sociabilidade urbana e apontam uma diversidade de agentes e suas estratégias, pressupondo novas dinâmicas de reprodução do espaço urbano e tornando evidente a tendência de fragmentação na cidade contemporânea, como visto na Figura 3.

\section{Figura 3 - Evolução urbana de Pelotas entre 1815 a 2015 e localização dos novos produtos imobiliários residenciais de 2009 a 2015}

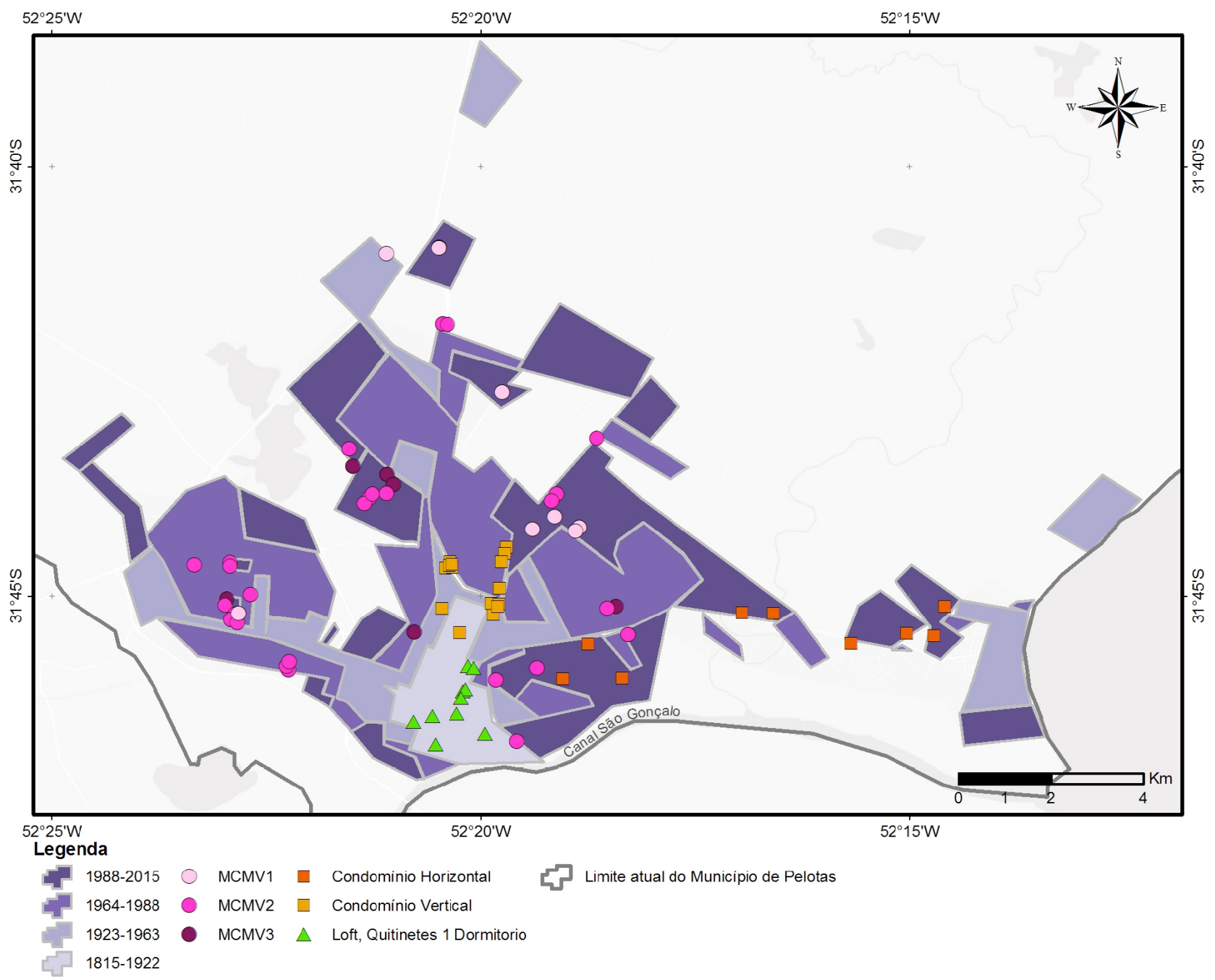

elaborado por: Éder Luís Rodrigues (2016). 
Como observamos ao longo desta exposição, os processos de periferização das camadas sociais de baixa e média renda em Pelotas, que remetem a diferentes momentos do processo histórico de produção do espaço urbano local, na atualidade passam por uma reafirmação a partir do domínio da produção mercantil da moradia popular, fomentado sobretudo pela política nacional de habitação intrinsecamente vinculada à matriz macroeconômica e anticíclica. Do mesmo modo, fenômenos recentes como o da suburbanização das camadas de média e alta renda, impulsionada pelo consumo de novos produtos imobiliários, a exemplo dos condomínios horizontais fechados, têm impelido a necessidade de ressignificação da relação entre periferia e centralidade, já que a incorporação desses artefatos na malha urbana reforçam a formação de policentralidades e a dicotomia entre conjunção e disjunção do tecido social e urbano, ratificando, assim, a forma urbana como um grande patchwork ou colcha de retalhos. Por sua vez, os processos simultâneos de abandono dos centros tradicionais por parte das atividades produtivas e de usos habitacionais tradicionais da cidade industrial, concomitantemente à promoção de novos usos nos quais se destaca o consumo diferenciado do espaço por meio do estímulo à formação de novos nichos de mercado, como no caso da "Cidade Universitária", reivindicam, por sua complexidade, uma análise profunda sobre os fenômenos contemporâneos de descentralização, recentralização e gentrificação dos antigos espaços de produção.

\section{Considerações finais}

A expansão do setor imobiliário verificada nos últimos anos está cada vez mais atrelada à atuação do Estado - pela execução de grandes obras de infraestrutura e de políticas anticíclicas - e aos organismos financeiros, o que permite maior dinâmica do setor na produção do espaço intraurbano nas cidades brasileiras. Em Pelotas, as empresas do ramo da construção civil e imobiliário orientam sua produção de modo diversificado, atendendo a demanda de diferentes segmentos de renda, o que, por sua vez, resulta numa diversidade de tipologias habitacionais na paisagem urbana e na profusão de novos processos socioespaciais que se destacam na estrutura da cidade.

Nesse cenário de transformações decorrentes, por um lado, da redução da atividade industrial na cidade, que agravou os problemas socioeconômicos locais, e, de outro, das transformações de processos globais e nacionais que se materializam em lugares específicos, identificamos algumas tendências que marcam uma transformação nos padrões de organização, apropriação e produção do espaço urbano em Pelotas, gerando dinâmicas diferentes daquelas que traduziam uma lógica própria da cidade industrial.

Como destacamos, são novas dinâmicas que se somam às características pretéritas de segregação social e funcional do espaço. No entanto, no novo contexto temporal das relações sociais de produção, o espaço intensifica os padrões anteriores assumindo formas mais complexas e hibridas, influenciadas por processos exógenos em articulação com as respostas desenvolvidas no âmbito local. Assim, procuramos destacar brevemente algumas das transformações observadas à luz da especificidade histórico-geográfica da cidade de Pelotas, evidenciando que a fragmentação social do espaço se destaca como principal característica desse novo momento. A cidade se conforma como um grande mosaico, no qual as zonas tradicionais da cidade industrial já não apresentam uniformidade, continuidade nem homogeneidade social e funcional. São processos de difícil identificação e conceituação, tendo em vista que eles se agregam e se misturam simultaneamente numa mesma espacialidade. 


\section{Referências}

ABRAMO, P. A cidade Com-fusa: a mão inoxidável do mercado e a produção da estrutura urbana nas grandes metrópoles latino-americanas". Revista Brasileira de Estudos Urbanos e Regionais/Anpur, v. 9, n. 2, p. 25-53, 2007.

AQUECIMENTO do setor imobiliário movimenta economia de Pelotas. Porto Alegre: Grupo RBS. Jornal Zero Hora, 5 jul. 2012. Disponível em: http://zh.clicrbs.com.br/rs/ noticias/noticia/2012/07/aquecimento-do-setor-imobiliario-movimenta-economia-de-pelotas-3812906.html. Acesso em: 26 ago. 2012.

CAIXA ECONÔMICA FEDERAL. Demanda Habitacional no Brasil. Brasilia, 2011.

CARLOS, A. F. O lugar no/do mundo. São Paulo: FFLCH, 2007.

CHIARELLI, L. M. A. Habitação social em Pelotas (1987 - 2010) influências das políticas públicas na promoção de conjuntos habitacionais. Tese (Doutorado em História) - Faculdade de Filosofia e Ciências Humanas, Pontifícia Universidade Católica do Rio Grande do Sul, Porto Alegre, 2014.

CORRÊA, R. L. O espaço urbano. São Paulo: Ática, 1993.

DOMINGUES, M.; CARVALHO, D.; CARVALHO, A. O Polo Naval e Offshore e o desenvolvimento regional na Metade Sul do Rio Grande do Sul. Ensaios FEE, Porto Alegre, v. 34, p. 933-954, 2013. Número Especial.

FEIJÓ, F; MADONO, D. Polo Naval do Rio Grande: potencialidades, fragilidades e a questão da migração. Porto Alegre: UFRGS/FCE/Deri, 2013.

FERREIRA, L. S. Setor de conservas da região de Pelotas-RS: mudanças na produção e conservadorismo nas relações de trabalho. Revista em Debate, Florianópolis, n. 5, p. 47-63, 2011.

HARVEY, D. O enigma do capital e as crises do capitalismo. São Paulo: Boitempo, 2011.

A produção capitalista do espaço. São Paulo: Annablume, 2005.

IBGE. INSTITUTO BRASILEIRO DE GEOGRAFIA E ESTATÍSTICA. Censo Demográfico 2010. Rio de Janeiro: IBGE, 2010.

. INSTITUTO BRASILEIRO DE GEOGRAFIA E ESTATÍSTICA. Censo Demográfico 2000. Rio de Janeiro: IBGE, 2000.

LEY, D.; MERCER, J. Locational conflict and the politics of consumption. Economic Geography, v. 56, n. 2, p. 89-109, abr. 1980.

MARQUES, M. G. Pelotas registra grande crescimento habitacional nos últimos dez anos. Diário Popular, Pelotas, 13 jan. 2013. Disponível em: http://www.diariopopular.com. $\mathrm{br} /$ index.php?n_sistema $=3056 \mathcal{E}$ id_noticia $=$ MjM0NA $==E$ id_area $=N Q==\% 20$. Acesso em: 16 maio 2014.

MATTOS, C. A. Modernización capitalista y transformación metropolitana en América Latina: cinco tendencias constitutivas. In: LEMOS, A. I.; ARROYO, M.; SILVEIRA, M. L. (Org.). América Latina: cidade, campo e turismo. Buenos Aires: Clacso; São Paulo: USP, 2006. p. 41-76. 
MENDES, L. Cidade pós-moderna, gentrificação e a produção social do espaço fragmentado. Cadernos Metrópole, São Paulo, v. 13, n. 26, p. 473-495, 2011.

MOURA, R. M. G. R. Habitação popular em Pelotas (1880-1950): entre políticas públicas e investimentos privados. Tese (Doutorado em História) - Faculdade de Filosofia e Ciências Humanas, Pontifícia Universidade Católica do Rio Grande do Sul, Porto Alegre, 2006a.

Moradia popular e expansão urbana: as vilas proletárias pelotenses. História em Revista, Pelotas, v. 12, p. 79-96, dez. 2006 b.

; CHIARELLI, L. M. A. Novas configurações urbanas a partir da implantação de conjuntos habitacionais em Pelotas-RS. Revista Projetare, Pelotas, n. 4, p. 120-131, nov. 2011.

PEREIRA, P. C. X. Agentes imobiliários e reestruturação: interesses e conflitos na construção da cidade contemporânea. In: PEREIRA, P. C. X. (Org.). Negócios imobiliários e transformações socioterritoriais em cidades da América Latina. São Paulo: FAU-USP, 2011. p. 23-31.

PREFEITURA MUNICIPAL DE PELOTAS. Plano local de habitação de interesse social. Pelotas, 2012

SÁ BRITTO, N. D. Industrialização e desindustrialização do espaço urbano em

Pelotas-RS. Dissertação (Mestrado em Geografia) - Instituto de Ciências Humanas e da Informação, Universidade Federal do Rio Grande, Rio Grande, 2011.

SAlGUEIRO, T. B. Cidade Pós-moderna: espaço fragmentado. Revista território, v. III, n. 4, jan./jun. 1998.

SHIMBO, L. Z. Habitação social, habitação de mercado: a confluência entre Estado, empresas construtoras e capital financeiro. Tese (Doutorado em Arquitetura) - Escola de Engenharia de São Carlos, Universidade de São Paulo, São Carlos, 2010.

SOARES, P. R. R. Produção imobiliária e crescimento urbano em cidades médias: Pelotas e Rio Grande-RS. In: SILVEIRA, R. L.; PEREIRA, P. X.; UEDA, V. (Org.). Dinâmica imobiliária e reestruturação urbana na América Latina. Santa Cruz do Sul: Edunisc, 2006. p. 159-192.

Del proyecto urbano a la producción del espacio: morfología urbana de la ciudad de Pelotas, Brasil (1812-2000). Tese (Doutorado em Geografia) - Departamento de Geografía Humana, Universidad de Barcelona, Barcelona, 2002.

SOJA, E. W. Geografias pós-modernas: a reafirmação do espaço na teoria social crítica. Rio de Janeiro: Jorge Zahar, 1993.

VASCONCELOS, P. A. Contribuições para o debate sobre processos e formas socioespaciais nas cidades. In: VASCONCELOS, P. A.; CORREA, R. L.; PINTAUDI, M. (Org.). A cidade contemporânea: segregação espacial. São Paulo: Contexto, 2013. p. 17-37.

VIEIRA, S. G. A cidade fragmentada: o planejamento e a segregação social do espaço urbano em Pelotas. Pelotas: Editora da UFPEL, 2005. 